\section{OBJETIVOS
DE SEGURIDAD EN CIRUGÍA}

\section{Introducción a las Guías de Recomendaciones de Seguridad en Cirugía Plástica}

En el año 2009, se formó una alianza mundial para la seguridad del paciente, bajo el principio de "Cirugía segura, salva vida». La Organización Mundial de la Salud (WHO, por sus siglas en inglés) elaboró «WHO Guidelines for Safe Surgery 2009» (Guías para una Cirugía Segura). Las recomendaciones emitidas fueron bien aceptadas por la comunidad médica y su aplicación ha permitido reducir en más de $50 \%$ la morbimortalidad de los pacientes que son operados. Desde su creación, han tenido varias revisiones y actualizaciones, así también varias especialidades médicas las han adaptado a sus necesidades. Utilizando estos principios desde hace cinco años, hemos implementado Guías de Seguridad para el Paciente de Cirugía Plástica y elaborado infografías como guías rápidas, sencillas, con la información suficiente, que permitan al cirujano tomar una decisión de seguridad con sus pacientes; los médicos que busquen una mayor información de los temas tratados, podrán consultar el libro con las guías de la Organización Mundial de la Salud (OMS) (acceso libre) o los artículos que están incluidos en la bibliografía de este trabajo. Hemos dividido las guías en dos grandes capítulos: el primero con las infografías de los objetivos de seguridad en cirugía, dictados por la OMS y adaptados a la especialidad de Cirugía Plástica. El segundo con recomendaciones específicas para los procedimientos más frecuentes o de mayor riesgo de la especialidad. En este número sólo presentaremos los objetivos de seguridad en cirugía.

Las recomendaciones de seguridad de estas guías están dirigidas a todos los cirujanos plásticos; para alcanzar un mayor impacto y divulgación, las publicamos en inglés y español.

Como toda guía, requiere de revisiones y actualizaciones periódicas; asimismo, los comentarios que nos envíen los cirujanos que las usen, nos será de mucha utilidad, para darles mayor fundamento y hacerlas más eficaces.

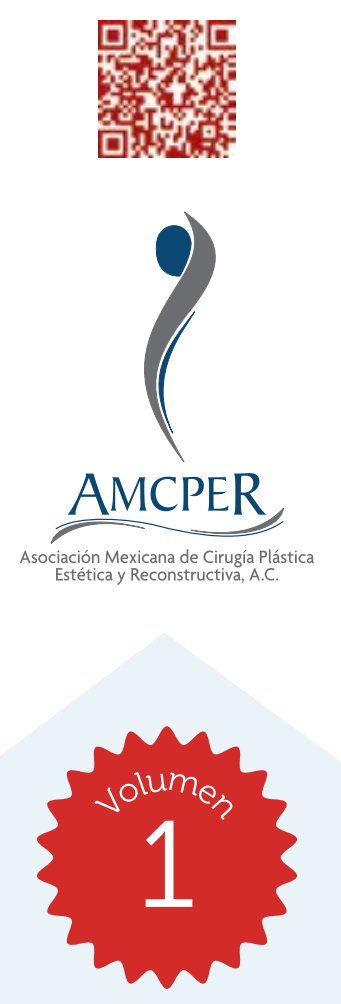

Dr. Jesús Cuenca Pardo, Dra. Ma. Isabel Caravantes C Dra. Livia Contreras Bulnes,

Dr. Guillermo Ramos,

Dr. Ernesto Theurel,

Dr. Rufino Irribarren,

Dr. Martín Morales,

Dra. Estela Vélez,

Dr. Eugenio Rodríguez Olivares

Diseño:

Liz Cárdenas Jonathan Morales

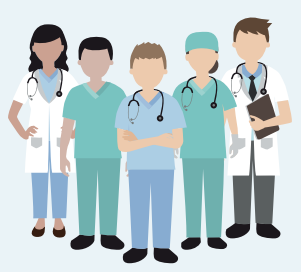

El diseño original de las infografías incluidas en este número de Cirugía Plástica fue modificado y adaptado al formato de la revista. Sin embargo, los contenidos originales no fueron alterados.

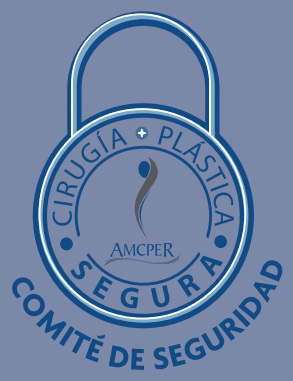

¿Tienes algún paciente con complicaciones? ¿Necesitas ayuda? ¿Orientación técnica? ¿Presencia de un experto que te ayude? ¡No dudes, comunícate con nosotros! 


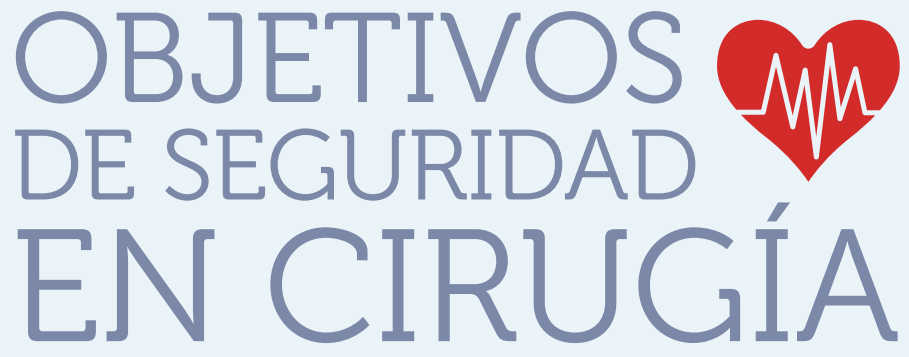

$1^{\circ}$ Objetivo de seguridad

Seguridad en Cirugía Plástica

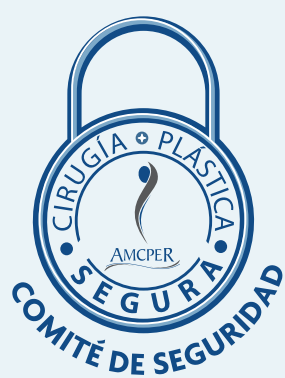

El cirujano debe supervisar y corroborar que se cumpla con los requerimientos anotados en esta lista de cotejo (sign in, time out).

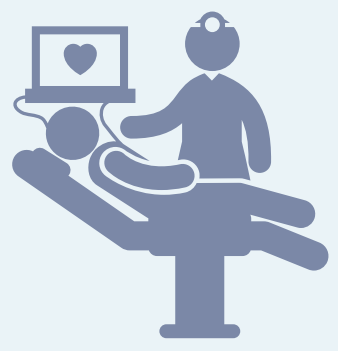

Lugar, paciente y procedimientos correctos.

«Surgical Safety Checklist»

\section{Paciente correcto}

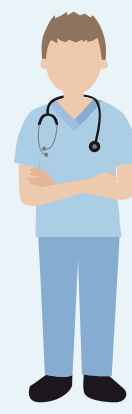

Identificación del paciente: con brazaletes o pulseras y marcar el sitio quirúrgico.

Valoración integral: incluir factores de riesgo y valoración funcional cardio-respiratoria.

Comunicación efectiva: con el paciente y sus familiares.

Carta de consentimiento informado y firmado: por procedimiento programado, explícita, identificando los riesgos y las alternativas de tratamiento. Verificar que la lean y firmen los pacientes y sus familiares.

\section{Quirófano correcto}

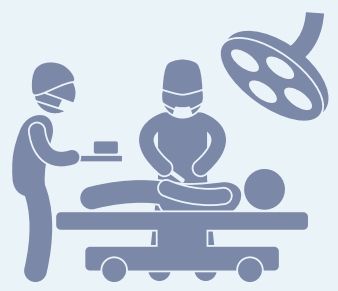

El monitoreo perioperatorio:

Detecta hasta $87 \%$ de los problemas anestésicos y disminuye la

mortalidad y las complicaciones en los pacientes quirúrgicos.

Los procedimientos quirúrgicos realizados

en clínicas pueden ser seguros:

- Si los quirófanos cuentan con todos los recursos y tienen la autorización por el órgano sanitario gubernamental correspondiente.

- Cirugías menores o moderadas.

- Pacientes ASA I.

- Procedimientos con baja incidencia de complicaciones y muerte.

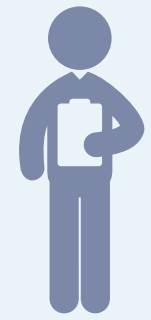

\section{Procedimiento correcto}

Los cirujanos plásticos hacen la mayoría de los procedimientos correctamente, la meta es hacerlo en todos los pacientes y todas las veces.

- El exceso de confianza, múltiples procedimientos quirúrgicos, el cansancio y la falta de comunicación efectiva con el equipo son las causas más frecuentes de complicaciones.

- Un equipo comprometido y con experiencia pueden detectar riesgos y evitarlos. El cirujano debe supervisar y corroborar que se cumpla con los requerimientos anotados en las Listas de Seguridad, ya que es el principal responsable en reducir el riesgo quirúrgico a sus pacientes. 


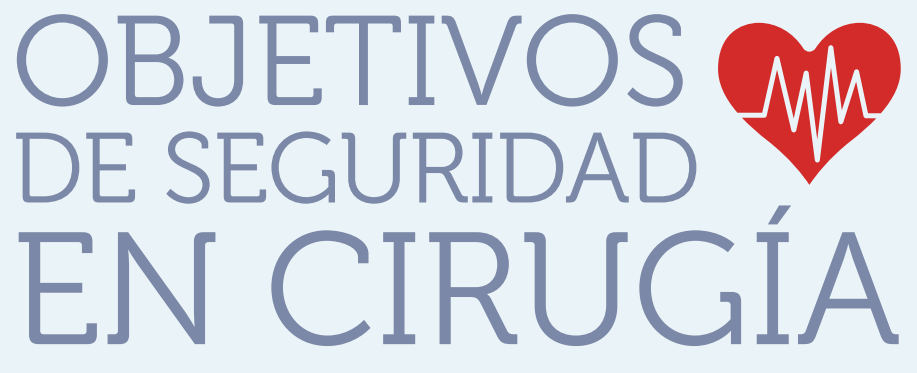

$2^{\circ}$ Objetivo de seguridad

\section{Prevenir el daño por anestesia}

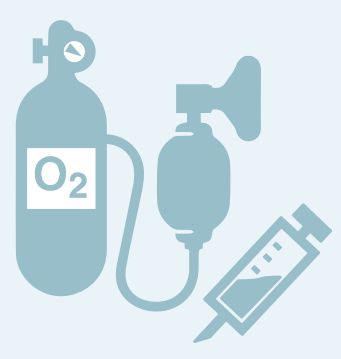

La causa más frecuente de las complicaciones mortales en el paciente quirúrgico es debido a los procedimientos anestésicos.

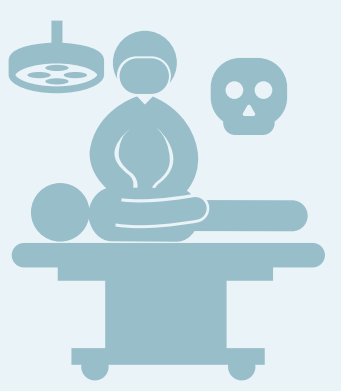

La mortalidad atribuible a la anestesia va desde 1:5,000 en países en desarrollo hasta 1:80,000 1:100,000 en países desarrollados. Los pacientes con cirugías menores o ASA I tienen mínimo riesgo.

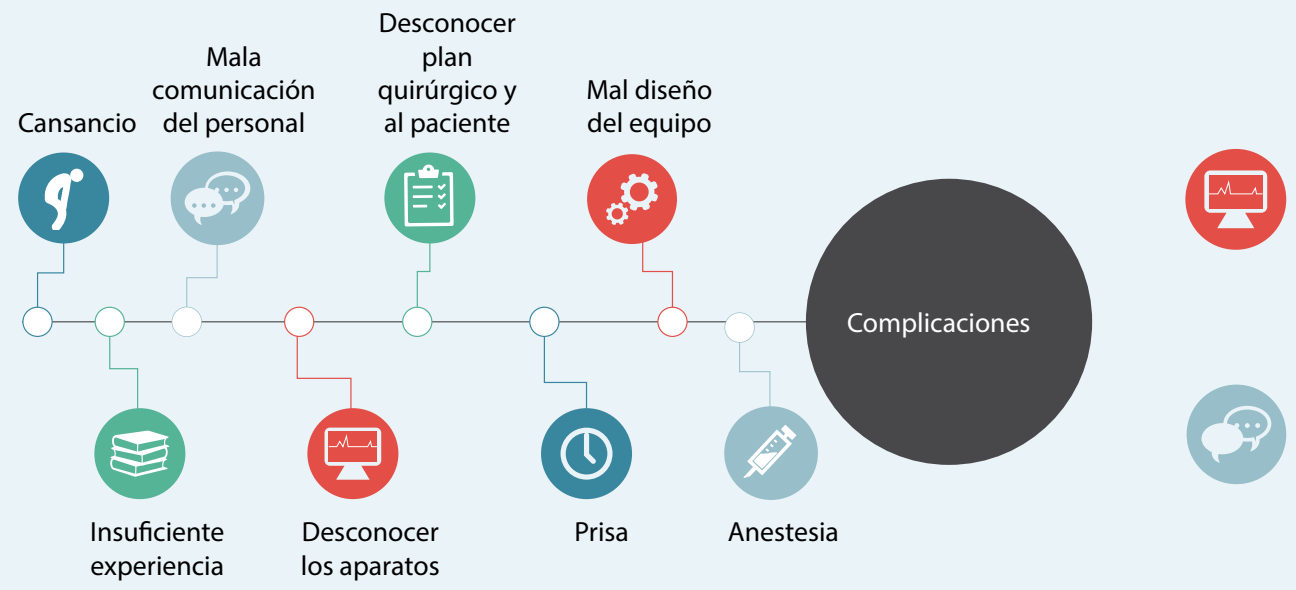

La falta de monitorización estricta, durante la anestesia, tiene hasta 1,000 veces más posibilidad de complicaciones.

La falta de comunicación efectiva entre todos los integrantes del equipo quirúrgico es responsable del $70 \%$ de las complicaciones quirúrgicas.

\section{Recomendaciones de Seguridad Anestésica en Cirugía Plástica}

- Anestesiólogo con experiencia en Cirugía Plástica.

- Valoración integral: buscar factores de riesgo y valoración dinámica.

- Monitoreo constante, perioperatorio. Incluir oximetría y capnografía de la función cardiorrespiratoria.

- Aparatos funcionando, verificar mantenimiento.

- Instalaciones seguras.

- Vía aérea permeable.

- Contar con botiquín con soluciones y medicamentos de reanimación.
- Analizar complicaciones con todo el equipo quirúrgico.

- Anestesiólogo integrado al equipo quirúrgico.

- Comunicación efectiva en el equipo quirúrgico.

- Iniciar la cirugía, sólo si el paciente se encuentra estable.

- Cumplir con las metas internacionales de seguridad.

- Lista de cotejo de seguridad completa.

- El tipo de anestesia lo debe decidir el anestesiólogo.

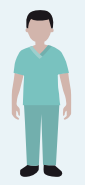

Es una garantía contar con un Anestesiólogo con experiencia en Cirugía Plástica, disponible e integrado al Equipo Quirúrgico.

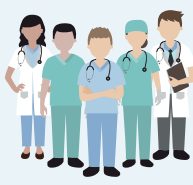

El equipo quirúrgico, cirujano, anestesiólogo y enfermeras son los responsables de la seguridad del paciente. 


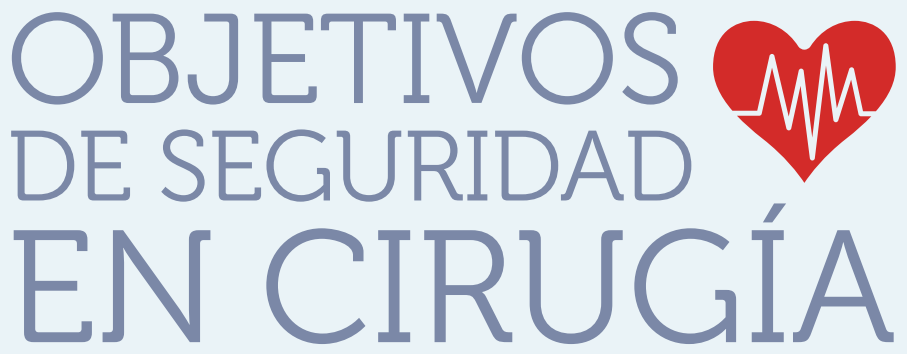

$3^{\circ}$ Objetivo de seguridad

la pérdida de la vía aérea o de la función respiratoria

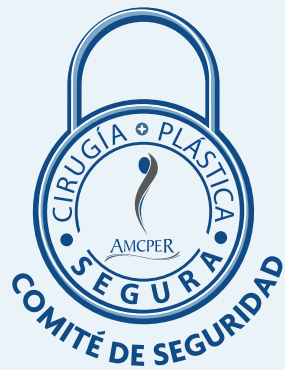

\author{
Causas más comunes de \\ resultados adversos \\ de una anestesia \\ - Ventilación inadecuada \\ - Intubación esofágica \\ - Intubación endotraqueal difícil \\ - Broncoaspiración
}

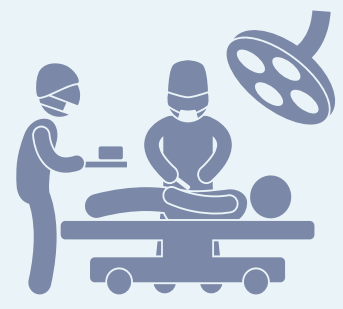

Evaluación de la vía aérea

Antecedentes

- Antecedentes de apnea de sueño y EPOC

- Antecedentes de anestesia previa con dificultad

- Obesidad

- Cuello corto y graso

- Presencia de placas, implantes o prótesis

\section{Factores primordiales que pueden ser prevenidos}

Cuando el anestesiólogo se enfrenta a una dificultad inesperada requiere de la resolución urgente de la ventilación con:

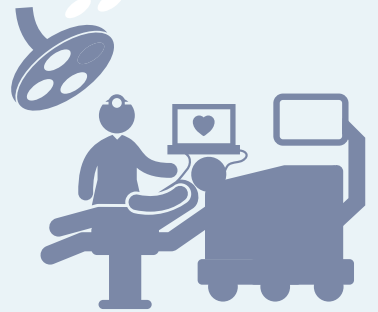

- Mascarilla facial

- Mascarilla laríngea

- Insistir en la entubación orotraqueal

- Intubación con fibra óptica

- Acceso quirúrgico
El éxito dependerá de la experiencia del equipo quirúrgico. ¡Existe una alta posibilidad de fracaso!

Para prevenir estas condiciones críticas, es necesario detectar a los pacientes con esta dificultad y estar preparados para su resolución.

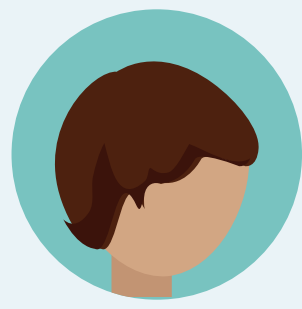

\section{Evaluación de la vía aérea}

Exploración

1. Distancia tiroides-mentón (Patil-Aldreti)

- Grado I: mayor a $6.5 \mathrm{~cm}$; sin dificultad para intubación

- Grado II: 6 a $6.5 \mathrm{~cm}$; dificultad moderada para intubar

- Grado III: menor a $6 \mathrm{~cm}$ : alta dificultad para intubar

2. Distancia mentón-esternón (prueba muy sensible)

- Menor a $12 \mathrm{~cm}$ : dificultad para entubar

3. Extensión de la cabeza

- Menor de 80 grados: dificultad para entubar

4. Hallazgos clínicos que pueden hacer sospechar dificultad de la vía aérea

- Protrusión mandibular

- Mentón pequeño (microretrognatia)

- Distancia entre incisivo superior e inferior mayor de $1 \mathrm{~cm}$

- Apertura de la boca limitada (menor de $4 \mathrm{~cm}$ )

- Imposibilidad para mover el labio

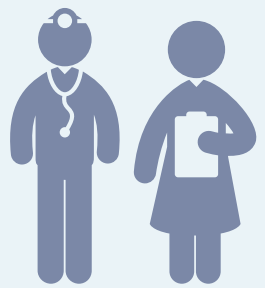

Para evitar una crisis con la vía aérea

- Es necesario la valoración preoperatoria del cirujano

- Detectar a los pacientes con vía aérea difícil

- Informar al anestesiólogo

- Valoración dirigida por el anestesiólogo, días previos a la cirugía

- El equipo quirúrgico deberá estar preparado para una eventualidad 
Tercer Objetivo. El equipo reconocerá y estará preparado para tratar la pérdida de la vía aérea o de la función respiratoria

\section{Evaluación de la vía aérea} Clasificación de Mallampati

Basado en el volumen de la lengua; las clases 3 y 4 tendrán mayor dificultad en la entubación orotraqueal.

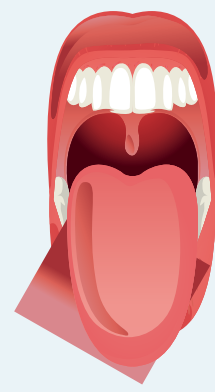

Clase 1

Paladar blando, fauces, úvula, pilares visibles

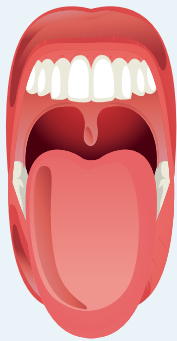

Clase 2

Paladar blando, úvula y fauces visibles

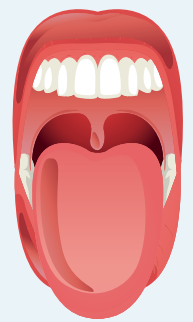

Clase 3 Paladar blando y base de la úvula visibles

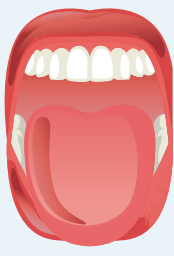

Clase 4 Paladar blando no es visible
Recomendaciones para el manejo de vía aérea difícil

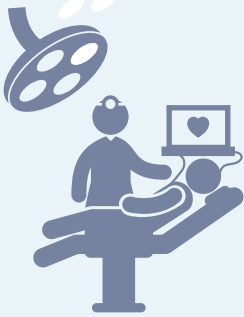

- Confirmar intubación endotraqueal

- Preparar una estrategia de extubación

- Si es una vía aérea difícil, considere el manejo del paciente mientras está despierto

\section{En pacientes con vía aérea difícil, días previos a la cirugía el anestesiólogo deberá:}

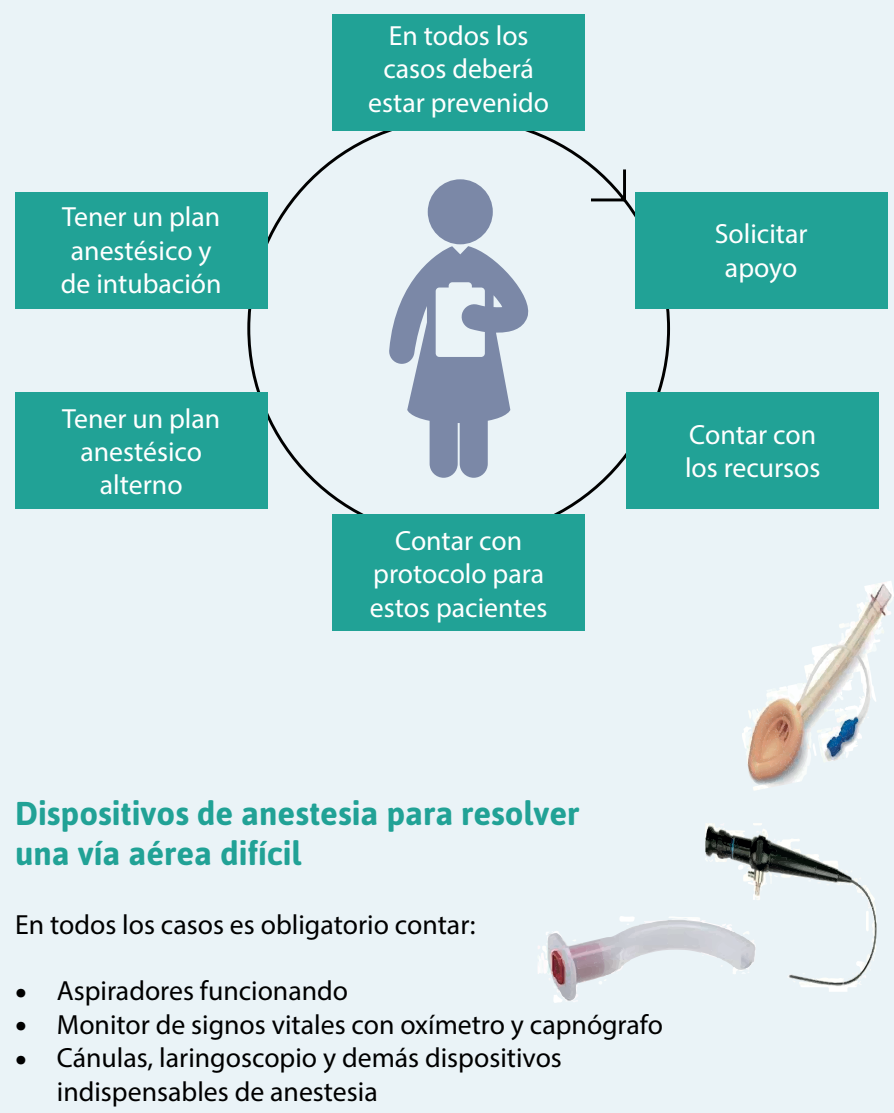

El requisito esencial para el manejo de una vía aérea difícil es un profesional capacitado con adecuada asistencia, un plan claro de acción y equipamiento adecuado. El anestesiólogo siempre deberá confirmar la colocación del tubo endotraqueal; escuchando sonidos respiratorios y con el uso de la capnografía.

Practice guidelines for management of the difficult airway. An updated report by the American Society of Anesthesiologists Task Force on Management of the Difficult Airway. Anesthesiology. 2003;98:1269-77.

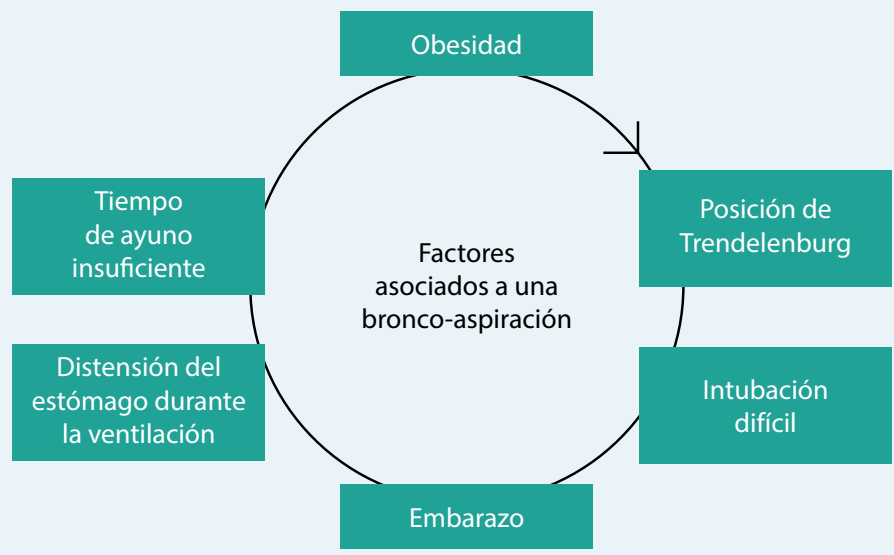

La bronco-aspiración del contenido gástrico es una severa complicación que puede presentarse durante una anestesia.

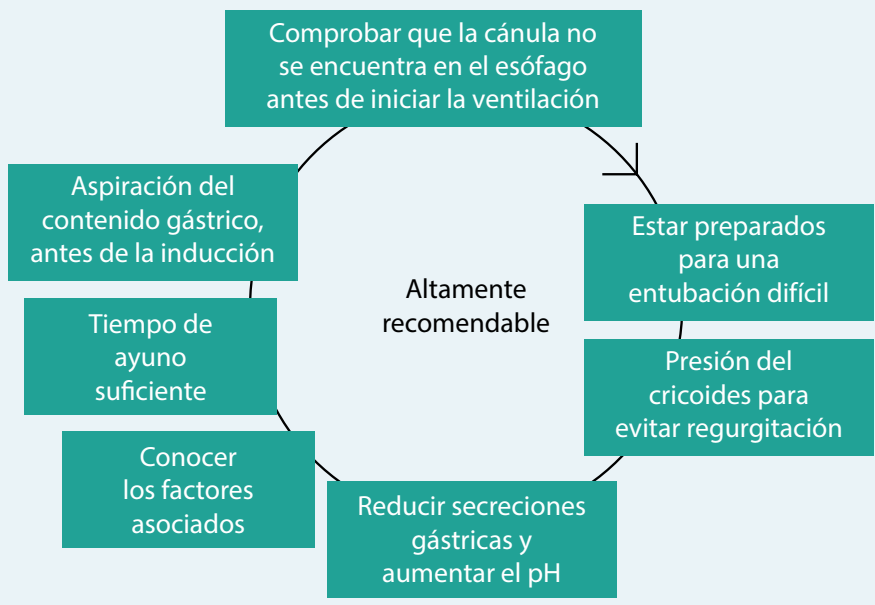




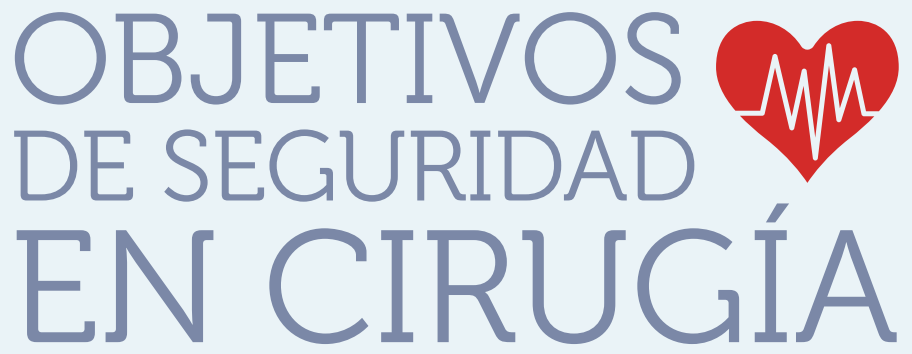

$4^{\circ}$ Objetivo de seguridad Prevenir y resolver la pérdida de sangre durante la cirugía

La pérdida de sangre se ha asociado a un pobre resultado quirúrgico.

La pérdida de sangre durante la cirugía puede tener consecuencias catastróficas. La identificación de la hipovolemia por pérdidas sanguíneas, su oportuno y adecuado manejo, disminuyen la morbimortalidad quirúrgica.

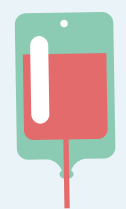

Para evitar la pérdida sanguínea; el equipo quirúrgico debe actuar en los tres periodos perioperatorios:

1. Preoperatorio

2. Transoperatorio

3. Postoperatorio

\section{Periodo preoperatorio}

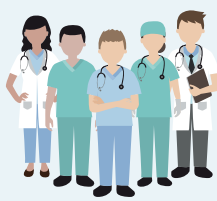

Se debe investigar anemia o alteraciones que puedan producir hemorragia durante la cirugía como:

- Discrasias sanguíneas

- Desnutrición

- Abuso de alcohol

- Antecedente de cirugía bariátrica

- Medicamentos antiagregantes plaquetarios

- Complementos con acción anticoagulante

- Terapia anticoagulante

- Hepatopatía

- Complementos alimenticios como: ajo, Garcinia Cambogia, ginseng, vitaminas

En pacientes asintomáticos, se han reportado en las valoraciones preoperatorias hallazgos anormales en las cifras de hemoglobina en un rango de $0.5-65.4 \%$ de los pacientes.

También en pacientes asintomáticos se encontraron anormalidades en las pruebas de coagulación en un rango de $0.06-21.2 \%$ de los pacientes.

Exámenes de laboratorio

a) Hemoglobina

b) Hematócrito

c) Pruebas de coagulación

d) Función hepática

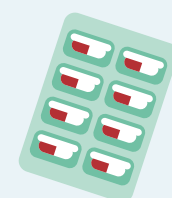

Calcular las probables pérdidas sanguíneas

Máxima pérdida sanguínea permisible, la fórmula usada es: Masa $=[($ hb-hb mínima) $/ \mathrm{hb}] \times$ (peso en kilogramos) $\times(\mathrm{mL}$ de sangre por kg de peso)

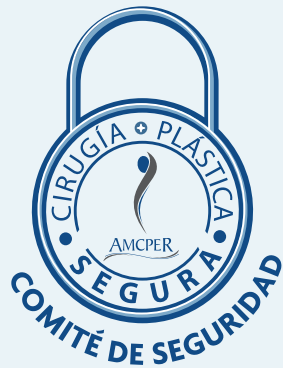

Objetivo:

1. El equipo quirúrgico reconocerá y se preparará para una pérdida elevada de sangre.

2. En cirugía plástica es recomendable evitar el sangrado excesivo y la formación de hematomas.

Procedimientos en cirugía plástica con posibilidad

de grandes pérdidas del volumen sanguíneo:

- Cirugía craneofacial

- Cirugía ortognática

- Fracturas faciales

- Malformaciones arteriovenosas

- Transferencia microquirúrgica libre de tejido

- Cirugía de contorno corporal postbariátrica

- Liposucción

- Procedimientos estéticos combinados

Volúmenes promedio de sangre

Hombre adulto: $75 \mathrm{~mL} / \mathrm{kg}$

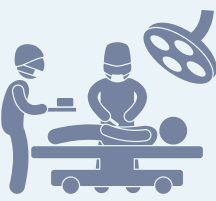

Mujer adulta: $65 \mathrm{~mL} / \mathrm{kg}$

Los anestesiólogos utilizan indistintamente

Del sexo: $70 \mathrm{~mL} / \mathrm{kg}$

Existen calculadoras del IMC en Internet

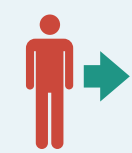

En pérdidas mayores al $20 \%$ del volumen sanguíneo:

$\square$ Contar con donadores de sangre

$\checkmark$ Tener sangre disponible durante la cirugía

$\square$ Valorar la autotransfusión

Recomendaciones preoperatorias:

- Antes de la cirugía se debe asegurar un estado de coagulación satisfactorio.

- Suspender antiagregantes plaquetarios 10 días antes de la cirugía.

- Suspender complementos dos semanas previas a la cirugía.

- Se deberá determinar el sangrado permisible y calcular el sangrado esperado por el procedimiento.

- Si se espera un sangrado mayor al permisible, tener sangre disponible y valorar la posibilidad de autotransfusión. 


\section{Periodo transoperatorio}

- Realizar hemostasia cuidadosa

- Reponer pérdidas sanguíneas

- Mantener línea venosa permeable y de buen calibre

- Mantener normotérmico al paciente

- Corregir la acidosis

Existen diferentes métodos para calcular las pérdidas sanguíneas en el transoperatorio:

- Reporte del anestesiólogo del sangrado estimado

- Líquido aspirado

- Sangre contenida en gasas y compresas

- Manifestaciones clínicas

Cuantificación de pérdida sanguínea:

1. Reporte del anestesiólogo del sangrado estimado

2. Líquido aspirado

3. Sangre contenida en gasas y compresas

4. Manifestaciones clínicas

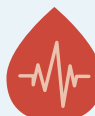

Cálculo de Meier y cols.

$$
E=\text { Volumen sanguíneo }-[(\text { volumen sanguíneo } \times \mathrm{hb2}) / \mathrm{hb} 1]
$$

Donde E es el volumen sanguíneo a reemplazar, hb1 la hemoglobina inicial, hb2 la hemoglobina final.

El volumen sanguíneo se calcula utilizando la fórmula:

$$
\text { VS }=0.414 \times \mathrm{T} 3+0.0328 \times \mathrm{BW}-0.03
$$

Donde T es la altura en metros y BW es el peso en kilogramos. Los cálculos de sangrado permisible y de la pérdida sanguínea quirúrgica son aproximados. Son manejados por anestesiología y en combinación con la

\begin{tabular}{|c|c|c|c|c|}
\hline & Clase I & Clase II & Clase III & Clase IV \\
\hline Pérdida sanguínea & $\leq 750 \mathrm{~mL}$ & $750-1,500 \mathrm{~mL}$ & $1,500-2,000 \mathrm{~mL}$ & $>2,000 \mathrm{~mL}$ \\
\hline $\begin{array}{l}\% \text { de volumen } \\
\text { perdido }\end{array}$ & $15 \%$ & $15-30 \%$ & $30-40 \%$ & $>40 \%$ \\
\hline Pulso & $<100$ & $>100$ & $>120$ & $>140$ \\
\hline Presión sanguínea & Normal & $\begin{array}{l}\text { Normal a } \\
\text { disminuida }\end{array}$ & Disminuida & $\begin{array}{l}\text { Notablemente } \\
\text { disminuida }\end{array}$ \\
\hline Estado mental & $\begin{array}{l}\text { Normal a un } \\
\text { poco ansioso }\end{array}$ & $\begin{array}{l}\text { Medianamente } \\
\text { ansioso }\end{array}$ & $\begin{array}{l}\text { Ansioso } \\
\text { y confuso }\end{array}$ & $\begin{array}{l}\text { Confuso o } \\
\text { letárgico }\end{array}$ \\
\hline Uresis & Normal & Reducida & Mínima & Nula \\
\hline $\begin{array}{l}\text { Reposición de } \\
\text { líquidos }\end{array}$ & Cristaloides & Cristaloides & $\begin{array}{l}\text { Cristaloides } \\
\text { y sangre }\end{array}$ & $\begin{array}{l}\text { Cristaloides } \\
\text { y sangre }\end{array}$ \\
\hline
\end{tabular}
clínica pueden ayudar a determinar el manejo.

Clasificación del choque hipovolémico asociado a pérdidas sanguíneas (from American College of Surgeons Advanced Trauma Life Support Manual) es de utilidad para el cálculo de pérdidas sanguíneas y la reposición de líquidos, en los periodos trans-y postoperatorio.
Además de la reposición de líquidos, el manejo de la pérdida sanguínea debe incluir:

- Control quirúrgico de la hemorragia

- Tratamiento de la coagulopatía

- Mantener la temperatura corporal

- Corrección de la acidosis

\section{Periodo postoperatorio}

Recomendaciones para evitar condiciones críticas del paciente por pérdida de sangre:

- Corrección de las pérdidas durante la cirugía

- Reversión cuidadosa de la anestesia

- Control de náusea y vómito

- Control del dolor (analgesia efectiva)

- Evitar los esfuerzos, reposo relativo

- Mantener al paciente normotenso

- Control de temperatura ambiental

- Exámenes de laboratorio postoperatorios

- Monitoreo estricto por 18 horas

- Buscar manifestaciones de choque hipovolémico

Bases perioperatorias para transfundir sangre a un paciente:

1. Criterios del manual «American College of Surgeons Advanced Trauma Life Support».

2. Pérdidas de 500 a $1,000 \mathrm{~cm}^{3}$ de sangre; valorar las condiciones generales del paciente.

3. Exámenes de laboratorio de biometría hemática, hematócrito y gasometría.

4. Disponibilidad de sangre.

\section{Recomendaciones antes de la cirugía:}

1. El anestesiólogo debe considerar la posibilidad de pérdida importante de sangre durante la cirugía.

2. Asegurar una vía intravenosa permeable y de buen calibre.

3. Discutir con todo el equipo quirúrgico el riesgo de pérdida importante de sangre.

4. Si el riesgo es desconocido, se debe preparar para una pérdida importante y tener sangre disponible.

5. Se debe garantizar la sangre suficiente, para recuperar las posibles pérdidas. 


\section{OBJETIVOS M EN CIRUGÍA}

$5^{\circ}$ Objetivo de seguridad

\section{El equipo evitará la} inducción de una alergia

\section{o reacción adversa a un} medicamento

\section{Errores de medicación}

- Prescripción

- Dispensación

- Administración

\section{Errores en la medicación:}

- Sustitución de una jeringa llena de medicamento por otra

- Incidente inadvertido

- Muchos errores no son reconocidos o reportados

- Reacciones adversas, en paciente susceptibles

- Efectos de sobredosificación

- Daño por omisión

- Omisión

- Repetición

- Sustitución (droga equivocada)

- Dosis incorrecta

- Velocidad de infusión incorrecta

- Paciente incorrecto

\section{Causas más frecuentes de anafilaxia:}

1. Antibóticos

2. Anestésicos

3. Opióides

4. Coloides

5. Látex
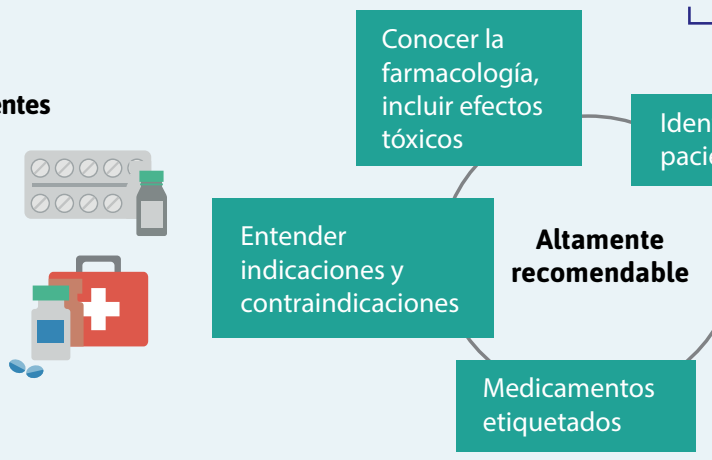

Seguridad en la medicación:

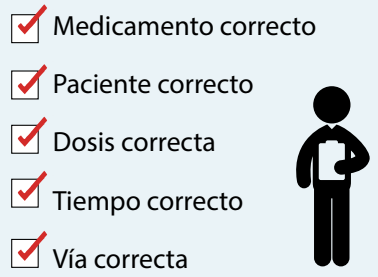

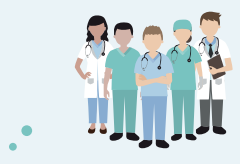

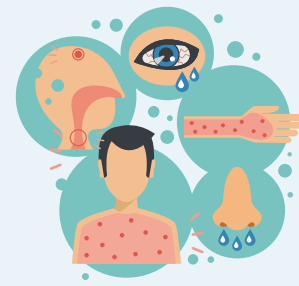

Errores en la preparación de soluciones:

- Cálculo de concentración

- Mezcla de soluciones

- Velocidad de infusión

- Drogas incompatibles

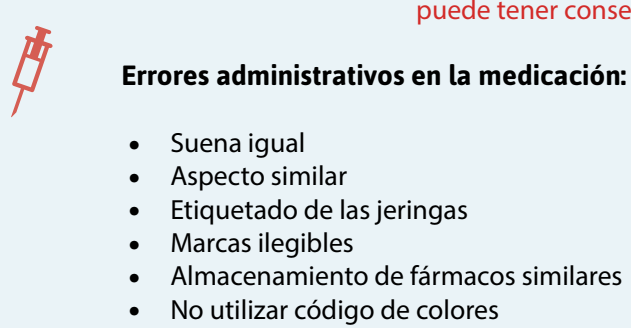

Tratamiento de la anafilaxia

Suspender medicamento

Antihistamínico

Identificar al

__ Hidrocortisona

L_ Adrenalina

paciente correcto
¿Es lo mismo? Adrenalina $=$ epinefrina

Errores en la administración de medicamentos durante la anestesia

Los errores en la administración de medicamentos durante una anestesia tienen una mortalidad de $24 \%$ y una morbilidad de $34 \%$.
Historia de

alergia o

sensibilidad

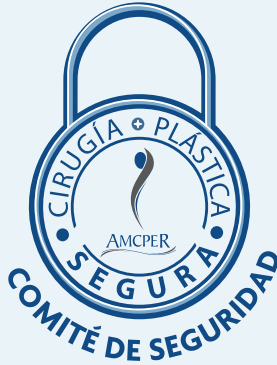




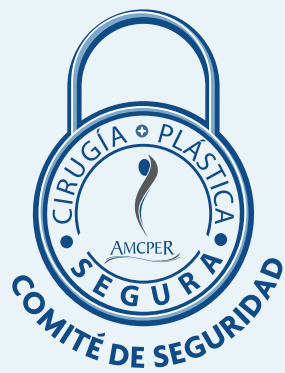

\section{Utilizar método para disminuir las infecciones}

\section{La infección del sitio quirúrgico representa de 2 a $15 \%$ de las infecciones hospitalarias}

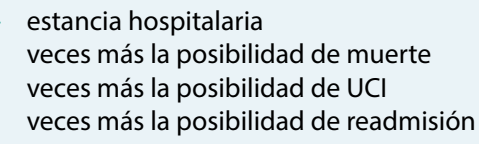

Características de una herida que incrementan las infecciones:

- Espacios muertos

- Presencia de suturas

- Presencia de cuerpos extraños

- Drenajes

La mayoría de infecciones son contaminación por la flora endógena

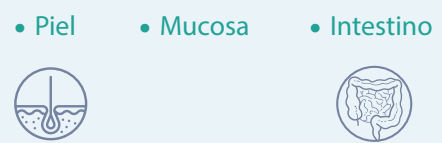

Tipos de infección del sitio quirúrgico Superficial Profunda Visceral

Factores que incrementan las infecciones

- Contaminación con bacterias de otros sitios como vías respiratorias o urinarias

- Bacterias locales con pobres defensas del huésped

- Inóculo mayor de 100,000 bacterias por gramo de tejido

- Bacterias locales o inóculo menor + suturas
Cantidad de bacterias $x$ virulencia Resistencia del huésped
Cantidad

de bacterias

Virulencia de

las bacterias

Infección

Sí/No 
Sexto Objetivo. Utilizar método para disminuir las infecciones

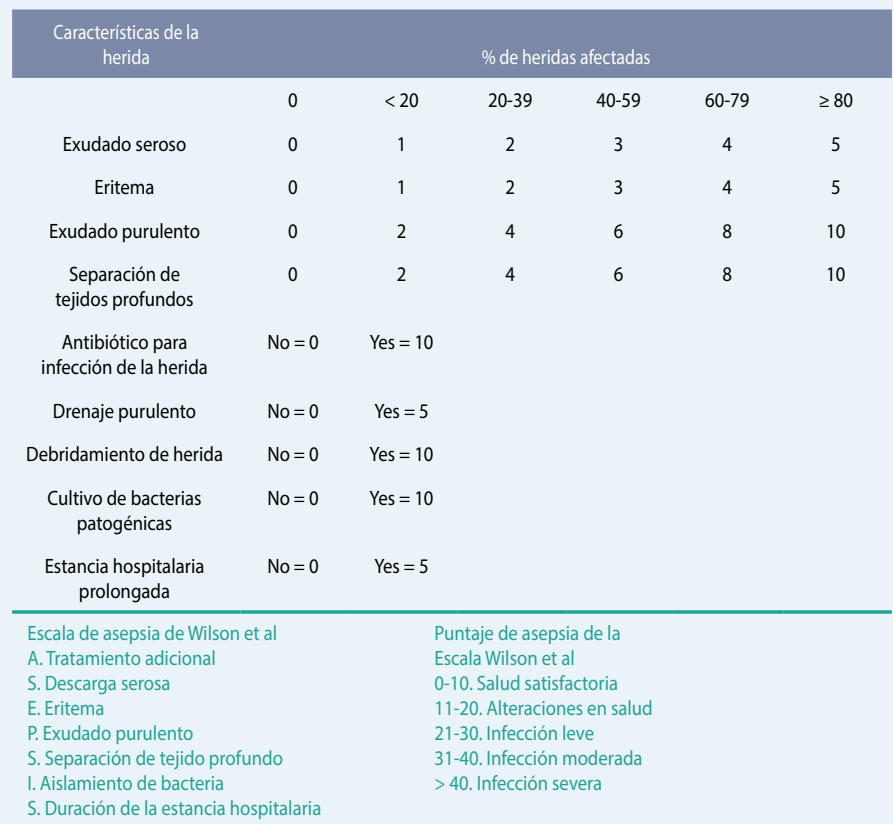

\section{Factores relacionados a la técnica:}

- Cirugía traumática

- Cirugía $>2$ horas

- Asepsia inadecuada de las manos

- Asepsia inadecuada del paciente

- Electrocoagulación excesiva

- Demasiadas suturas

- Sangrado excesivo

\section{Factores relacionados a los recursos:}

- Esterilización inadecuada

- Quirófanos contaminados

- Áreas no limitadas

- Aire contaminado

- Aire acondicionado

- Falta de profilaxis antibiótica

- Sangrado excesivo

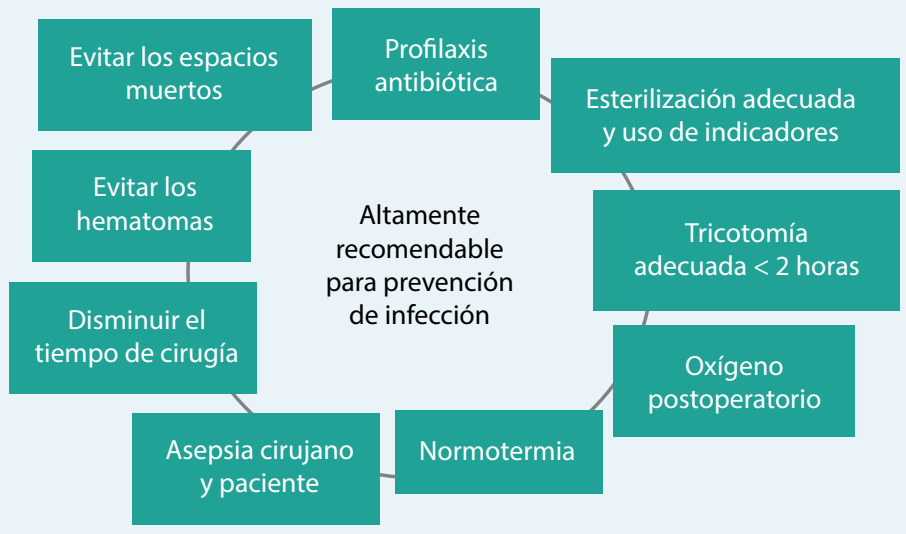

\section{Factores de riesgo de infección del paciente:}
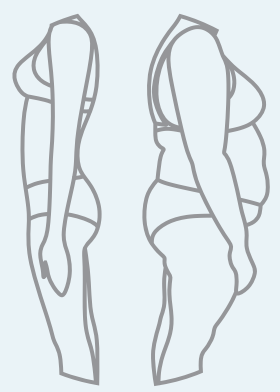

- Infecciones remotas

- Diabetes

- Tabaquismo

- Esteroides

- Obesidad

- Edad

- Nutrición

- Transfusión sanguínea

\section{Factores más importantes en la prevención de infecciones}

- Técnica quirúrgica depurada

- Técnica quirúrgica aséptica
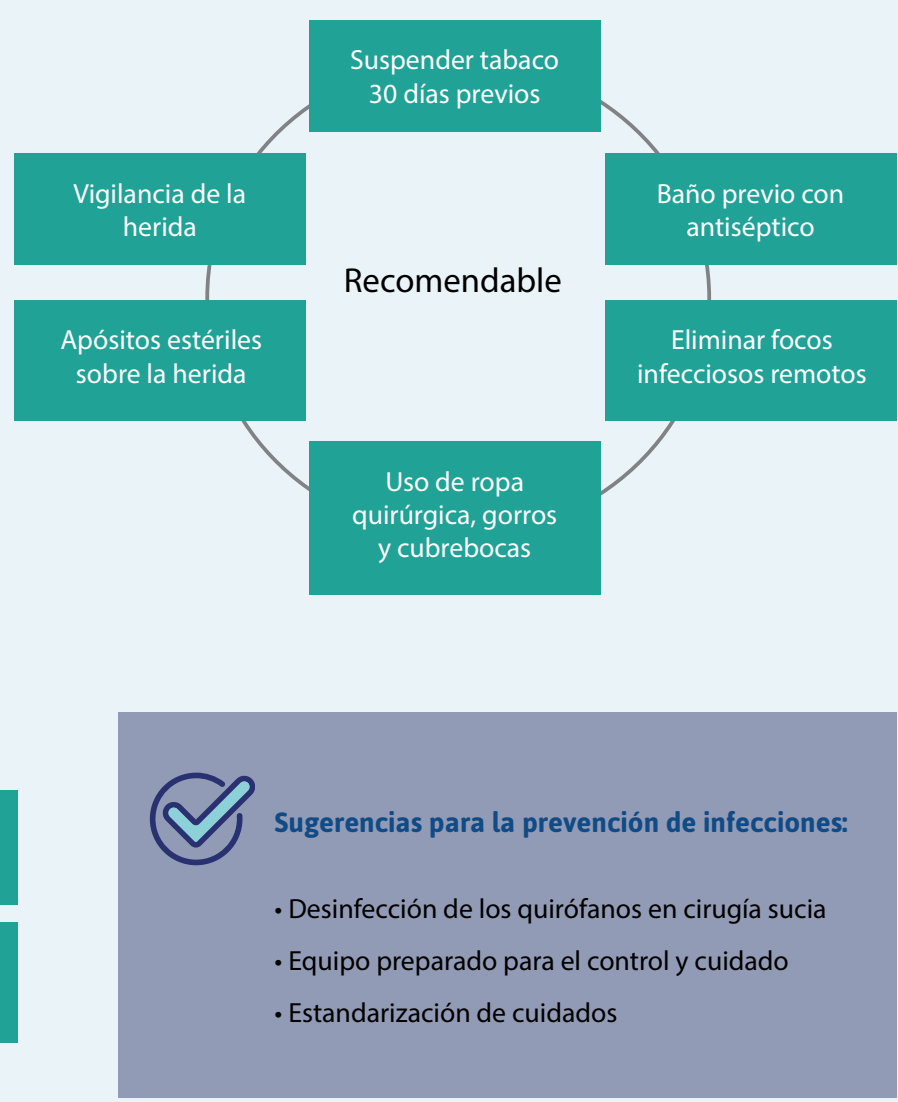


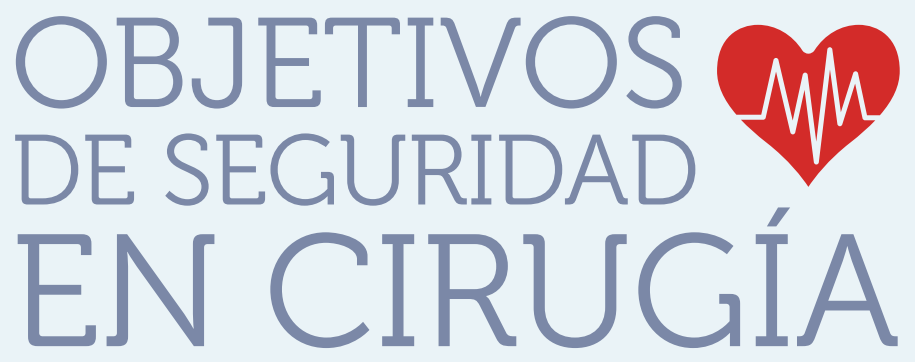

$7^{\circ}$ Objetivo de seguridad

Prevenir la retención inadvertida de instrumental y esponjas en la herida

Severo error quirúrgico; se calcula 1 caso en 5,000-19,000 cirugías. El mayor riesgo es una cirugía con gran sangrado, donde se utilizan muchos instrumentos y esponjas quirúrgicas.

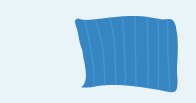

Esponjas quirúrgicas

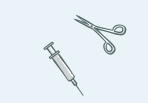

Instrumental

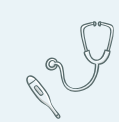

Accesorios

\section{Retención inadvertida de material}

Antes de iniciar la cirugía, contar todo el material e instrumental; hacerlo por ítems y por dos personas (circulante e instrumentista).

\section{Organizar y contar:}

- Cortante

- Instrumental

- Agujas

- Accesorios

- Esponjas

\section{Esponjas quirúrgicas seguras:}

- Con marcadores de RX

- Con marcadores de ultrasonido

- Código de barras o microchip

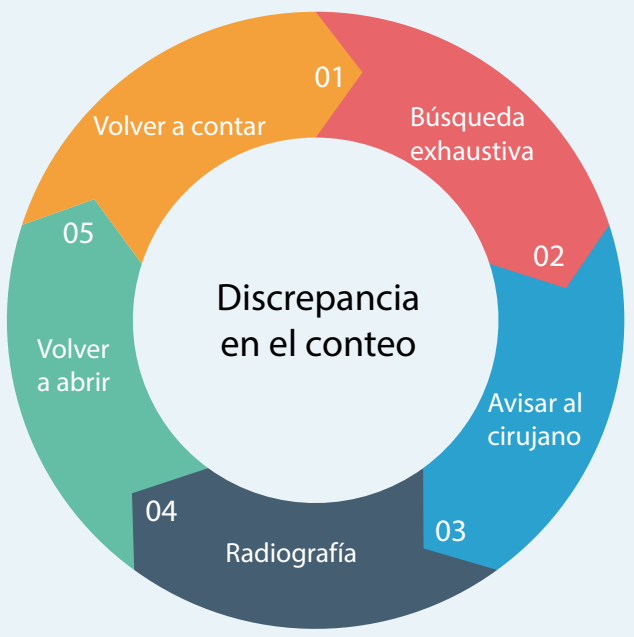

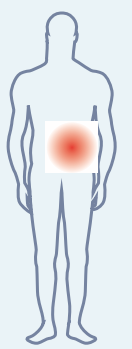

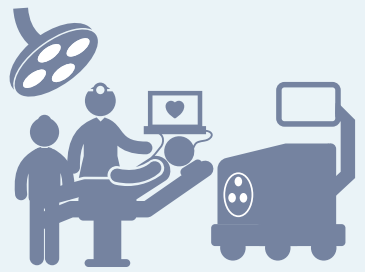

En $88 \%$ de los casos, de retención inadvertida de material quirúrgico, se reportó una cuenta completa.

\section{Causas de error en el conteo:}

- Fatiga del personal

- Distracciones

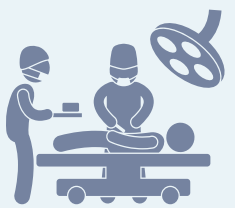

- Personal sin experiencia

- Personal ajeno al quirófano

- Comunicación no efectiva

\section{Inicio de} cirugía

- Organizar material

- Conteo

- Cortante

- Instrumental

- Agujas

- Accesorios

- Esponjas

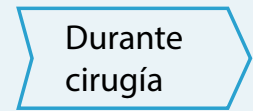

Término de cirugía

- Exploración antes del cierre

- Recuento de material

- Registro en expediente del conteo

\section{Altamente recomendable:}

- Conteo exhaustivo y completo realizado por instrumentista y circulante

- Exploración antes del cierre

- Cuenta al principio y al final de la cirugía

- La cuenta deberá ser registrada en el expediente

- Informar el resultado al cirujano 


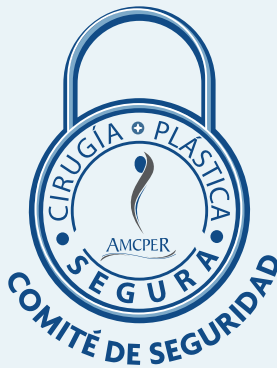

\section{El equipo asegurará e identificará con precisión}

\section{todos los especímenes quirúrgicos}

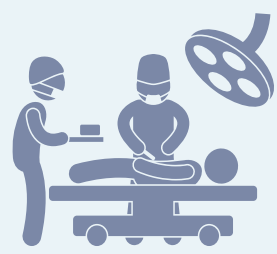

En un estudio de errores de identificación en muestras de laboratorio, de 417 instituciones de los Estados Unidos, casi 50\% se debió a errores de etiquetado. De cada 18 errores de marcaje uno termina en evento adverso. Se estima que cerca de 160,000 eventos adversos al año, ocurren en EE.UU. por mal etiquetado.

Muestras que requieren ser etiquetadas para su identificación en procedimientos de cirugía plástica.

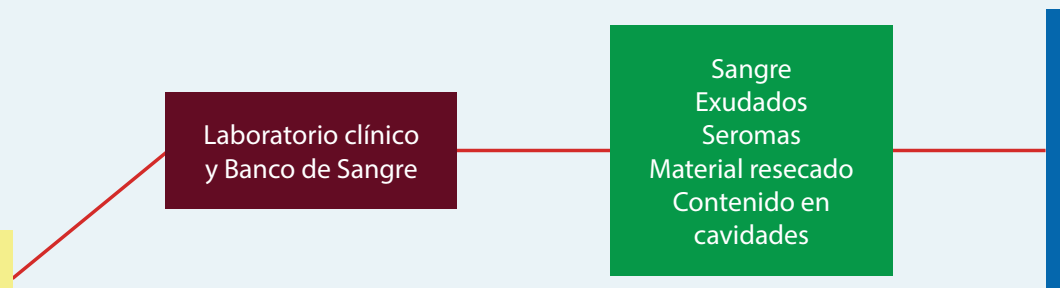

Sangre

Exudados

Seromas

Cavidades

\section{Exámenes frecuentes:}

Grupo sanguíneo y factor Rh

Pruebas cruzadas

Hematócrito y hemoglobina

Electrolitos, gases y $\mathrm{Ph}$, glucosa

Estudio citoquímico

Cultivos y PCR

\section{Para evitar errores:}

- Etiquetar adecuadamente el espécimen y la requisición.

- La correcta identificación del paciente en sus especímenes y formas de requisitado, son críticas para prevenir errores en el laboratorio clínico y de patología.

- Una mejor identificación es crucial para prevenir errores en el etiquetado de muestras de laboratorio.

- Bandas de identificación pueden disminuir las tasas de error de etiquetado de muestras.
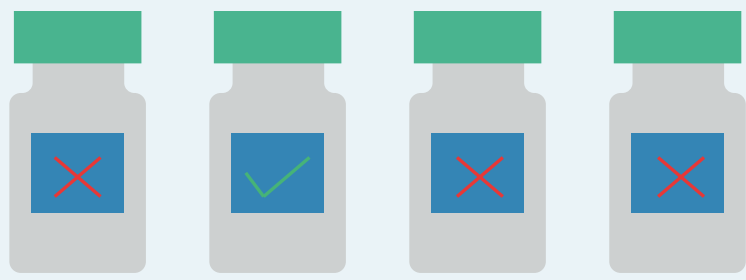

\section{Recomendaciones:}

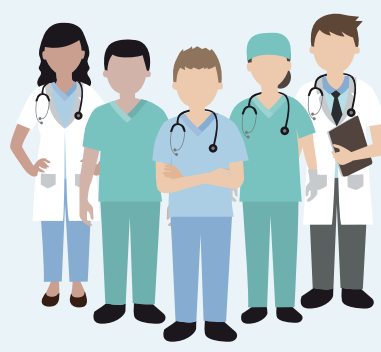

- El equipo debe confirmar que todos los especímenes quirúrgicos estén correctamente etiquetados con la identidad del paciente, el nombre del espécimen y su localización (lugar y lado) de donde el espécimen fue obtenido. Un miembro del equipo debe leer en voz alta la etiqueta y otro miembro confirmar verbalmente.

- El líquido de seroma periprotésico se coloca en tubo estéril con el etiquetado correcto. De seis a 12 horas en refrigeración. Mayor a 12 horas mezclar desde el inicio en carbowax en solución 1 a 1.

- Las cápsulas de los implantes en formol inmediatamente a ser extraídos solución 1 a 10, de 12 a 22 grados. Se envía a patólogo con experiencia para marcadores tumorales CD45, CD20, CD3, CD4, CD8, CD30, ALK-1, CD43 y EMA.

- Los tumores de piel con marcaje de bordes (superior o inferior) con

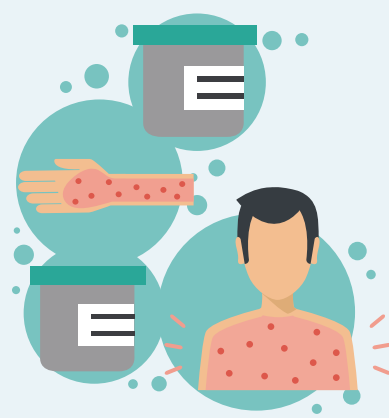
referencias de sutura, con el etiquetado correcto. 


\section{OBJETIVOS \\ DE SEGURIDAD \\ EN CIRUGÍA}

$9^{\circ}$ Objetivo de seguridad

Comunicación efectiva;

intercambio de información crítica

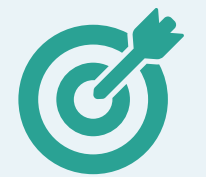

\section{El objetivo es crear un sistema robusto y práctico, frente a los riesgos humanos y operacionales}

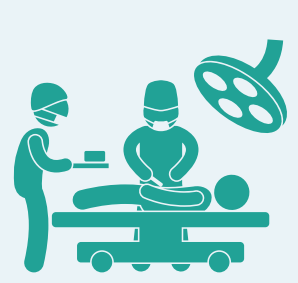

\section{Catástrofe:}

- Exceso de trabajo

- Conocimiento inadecuado

- Falta de habilidad y experiencia

- Pobre intercomunicación

- Falta de supervisión o de instrucciones

- Ambiente estresante

- Fatiga y cambios rápidos

\section{Omisión}

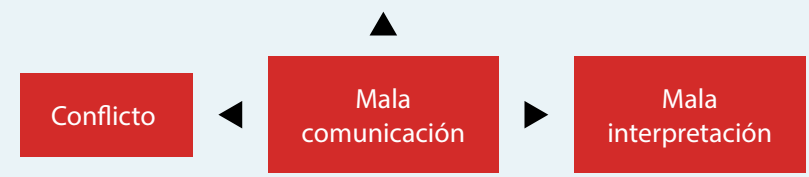

\section{Cultura de seguridad:}

- Estudio previo

- Planeación conjunta

- Equipo informado

- Verificación de listas de seguridad

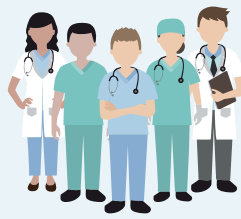

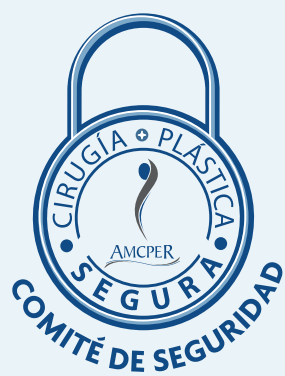

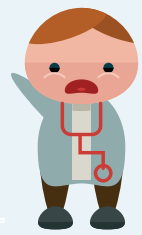

\section{¿Cuál es el origen de una catástrofe?}

- La mayoría de las catástrofes son por error humano.

- Las fallas técnicas pueden corregirse; las humanas minimizarse.

Falta de comunicación causa $70 \%$ de las complicaciones

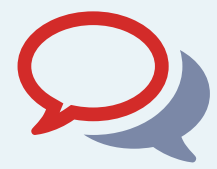

$$
\text { Comunicación }
$$

Estandarización

de las cirugías

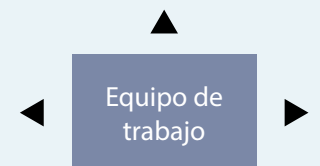

Cultura de seguridad

\section{Anestesiólogo deberá determinar:}

- Valoración preoperatoria

- Determinar el tipo de anestesia que utilizarán

- Determinar medicación preanestésica

- Momentos críticos en la seguridad

- Líquidos (sangre) que va a necesitar

- Enfermedades de riesgo del paciente

\section{Las enfermeras deberán determinar:}

- Contar el instrumental

- Permanecer en el quirófano hasta que el paciente salga de la sala

- Momentos críticos en la seguridad

- Las condiciones de los equipos, instrumental y material

- Etapas críticas de la cirugía

- Instrumental y material que necesita

- Análisis y discusión de la cirugía programada con el equipo quirúrgico 


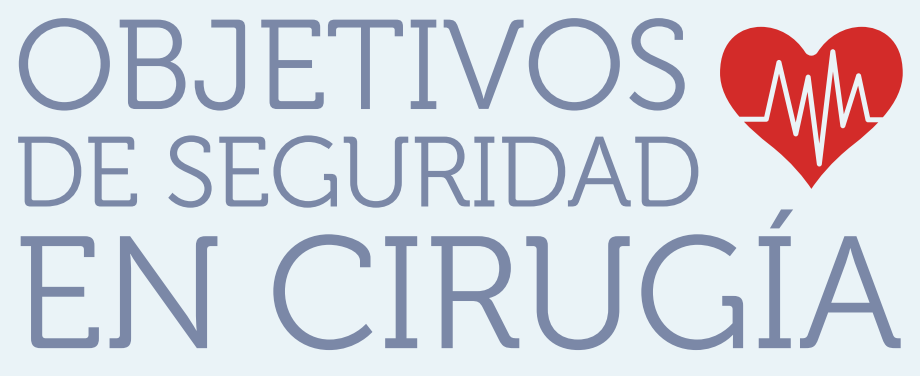

$10^{\circ}$ Objetivo de seguridad

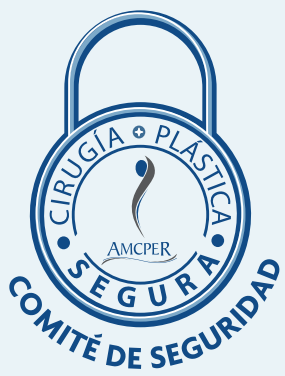

\section{Establecer un sistema de vigilancia de las cirugías}

\section{realizadas, sus resultados y complicaciones}

\begin{abstract}
La puntuación Apgar para cirugías es un sistema de medición simple de hasta 10 puntos para pacientes quirúrgicos, que sirve para darnos una retroalimentación sobre la condición del paciente después de su cirugía.
\end{abstract}

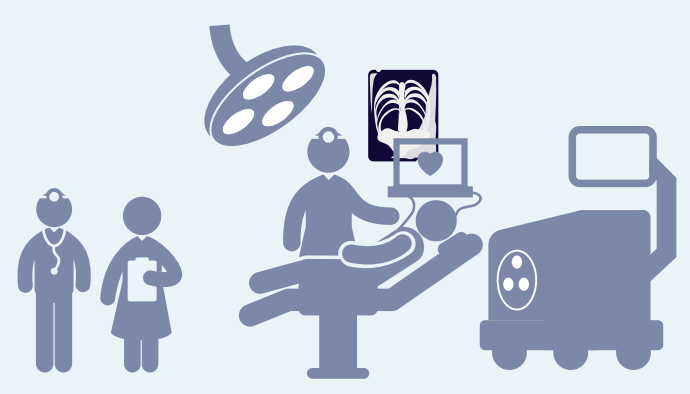

\section{La puntación está basada en 3 parámetros:}

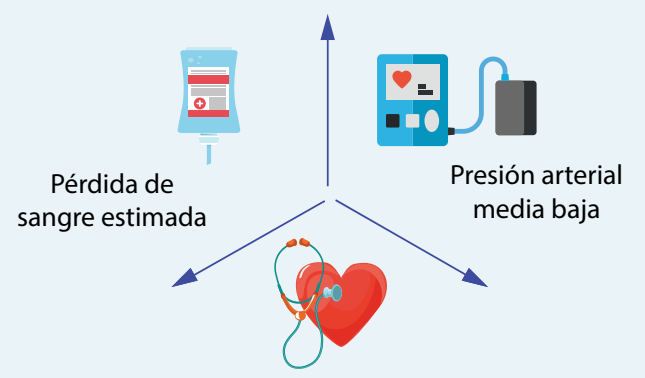

\begin{tabular}{|c|c|c|c|c|c|}
\hline & 0 puntos & 1 punto & 2 puntos & 3 puntos & 4 puntos \\
\hline $\begin{array}{c}\text { Pérdida de sangre } \\
\text { estimada }(\mathrm{mL})\end{array}$ & $>1,000$ & $601-1,000$ & $101-600$ & $\leq 100$ \\
\hline $\begin{array}{c}\text { Presión arterial media } \\
\text { baja }(\mathrm{mmHg})\end{array}$ & $<40$ & $40-54$ & $55-69$ & $\geq 70$ & $\leq 55$ \\
\hline $\begin{array}{c}\text { Frecuencia cardiaca } \\
\text { media baja } \\
\text { (latidos por minuto) }\end{array}$ & $>85$ & $76-85$ & $66-75$ & $56-65$ & \\
\hline
\end{tabular}

Frecuencia cardiaca

media baja

Por lo tanto, si un paciente tuvo una pérdida de sangre estimada de $50 \mathrm{~mL}$ (3 puntos), una presión arterial media baja de $67 \mathrm{mmHg}$ ( 2 puntos) y una frequencia cardiaca media baja de 56

(3 puntos), tendrá una puntuación total de 8 .

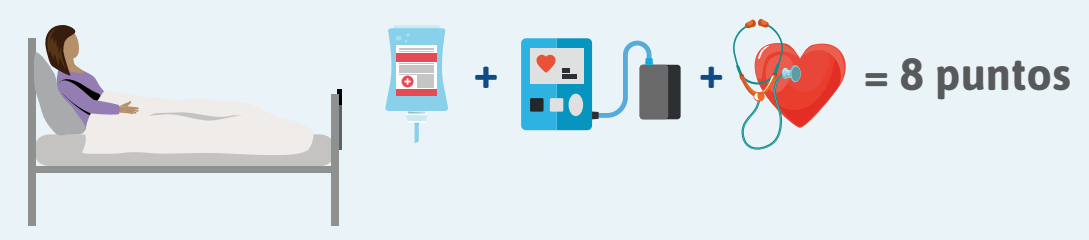

\section{Entre más puntos presente el paciente, mejor será el pronóstico de su recuperación y menores complicaciones tendrá después de la cirugía}

Está puntuación debe realizarse en los hospitales a TODOS los pacientes para detectar patrones de posibles complicaciones y analizar las diferentes capacidades quirúrgicas del personal médico, para así poder estandarizar en qué grupos de pacientes y en qué cirugías se presentarán complicaciones y entonces poderlas prevenir.
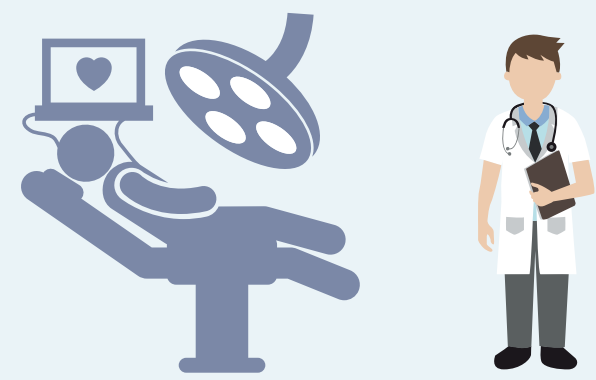


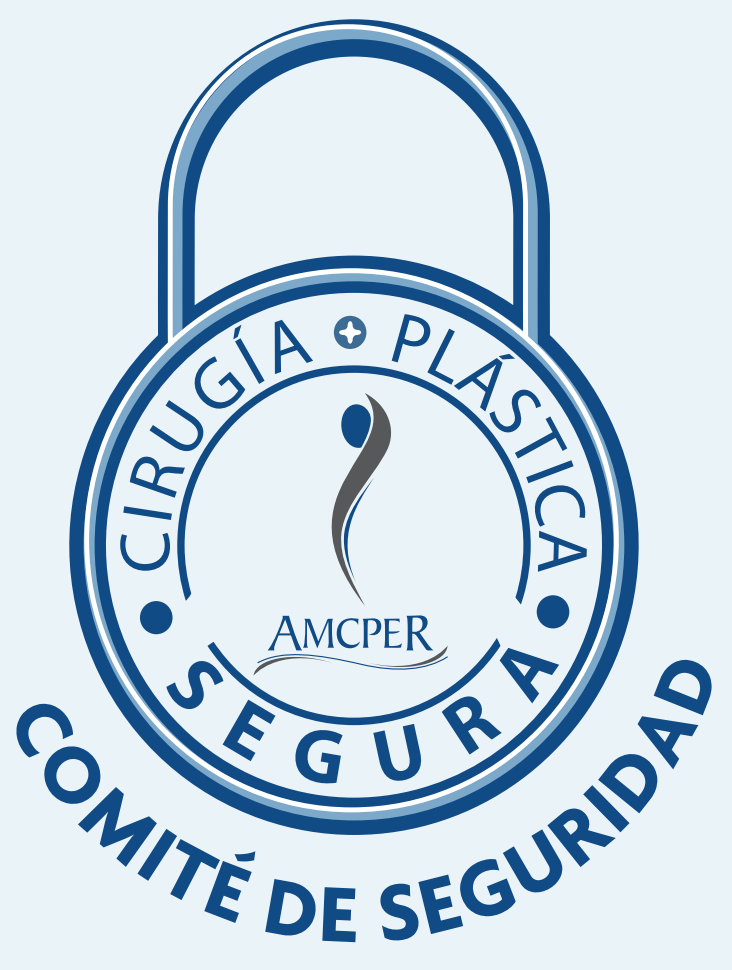

¿Tienes algún paciente con complicaciones? ¿Necesitas ayuda? ¿Orientación técnica? ¿Presencia de un experto que te ayude? ¡No dudes, comunícate con nosotros!

comitedeseguridad@amcper.org.mx 